\title{
Use of an Infectious cDNA Clone of Pepper Veinal Mottle Virus to Confirm the Etiology of a Disease in Capsicum chinense
}

\author{
Weiyao Hu, ${ }^{1} \mathrm{Li}$ Qin, ${ }^{1}$ Haixia Yan, ${ }^{2}$ Weiguo Miao, ${ }^{1}$ Hongguang Cui,,${ }^{1, \dagger}$ and Wenbo Liu ${ }^{1, \dagger}$ \\ ${ }^{1}$ Key Laboratory of Green Prevention and Control of Tropical Plant Diseases and Pests, Ministry of Education and College of Plant Protection, \\ Hainan University, Haikou, Hainan 570228, China \\ ${ }^{2}$ College of Forestry, Agricultural University of Hebei, Baoding, Hebei 071001, China \\ Accepted for publication 15 October 2019.
}

\begin{abstract}
The pepper cultivar Yellow Lantern, one of the spiciest pepper varieties, is a local germplasm of Capsicum chinense, cultivated exclusively on Hainan Island, China. However, this variety is susceptible to viral diseases that severely affect its production. In this study, we report that pepper veinal mottle virus (PVMV) is associated with foliar chlorosis and rugosity symptoms in Yellow Lantern. To verify this correlation, we constructed a full-length cDNA clone of a PVMV isolate named $\mathrm{HNu}$. The virus progeny derived from the cDNA clone replicated and moved systemically in the pepper, inducing the same symptoms as those induced by PVMV-HNu in
\end{abstract}

ABSTRACT

The pepper cultivar Yellow Lantern is a local germplasm of the domesticated species Capsicum chinense and is cultivated exclusively on Hainan Island, China. Yellow Lantern is widely used to prepare a canned sauce, a commercial favorite among local consumers and visiting tourists alike. With the increasing production of this pepper in Hainan, the associated viruses have become prevalent, severely threatening the Yellow Lantern-based industry. A total of five viral species, chilli veinal mottle virus (ChiVMV, Potyvirus), pepper veinal mottle virus (PVMV, Potyvirus), chilli ringspot virus (ChiRSV, Potyvirus), tobacco mosaic virus (TMV, Tobamovirus), and cucumber mosaic virus (CMV, Cucumovirus), have been reported in this pepper in Hainan (Liang et al. 2015; Wang 2012; Wang et al. 2006). Among these, mixed infections, with combinations of CMV/TMV, CMV/ChiRSV, CMV/ChiVMV, or ChiRSV/ChiVMV, occur commonly, accounting for $48.6 \%$ of all viral infections in Yellow Lantern plants (Wang 2012). PVMV is considered to be a major constraint to pepper production, which reduces yield and fruit quality (Fajinmi and Odebode 2010). The incidence of PVMV was found to be $74.07 \%$ during a diagnostic test conducted on 27 Yellow Lantern samples suspected of viral infections, collected from Wenchang and Wanning in Hainan (Liang et al. 2015), although a correlation between the virus and symptomatic phenotype was not confirmed.

†Corresponding authors: H. Cui; hongguang.cui@ hainanu.edu.cn, and W. Liu; saucher@hainanu.edu.cn

Funding: This study is supported by grants from the National Natural Science Foundation of China (31860487), Hainan Provincial Natural Science Foundation of China (318MS006), and the Scientific Research Foundation for Advanced Talents, Hainan University (No. KYQD(ZR)1734).

First and second authors contributed equally to this work.

*The $e$-Xtra logo stands for "electronic extra" and indicates that supplementary figures and tables and supplementary materials are published online.

The author(s) declare no conflict of interest.

(C) 2020 The American Phytopathological Society
Yellow Lantern peppers in the field. The results support that PVMV$\mathrm{HNu}$ is the causal agent of foliar chlorosis and rugosity disease in Yellow Lantern. This knowledge will help in the diagnosis and prevention of disease caused by PVMV. Furthermore, the cDNA clone serves as a reverse genetic tool to study the molecular pathogenesis of PVMV.

Keywords: Capsicum, cDNA clone, pathogenicity, pepper veinal mottle virus, Potyvirus

PVMV is classified in the genus Potyvirus of the family Potyviridae and shares similar morphological, biological, and genomic characteristics with other potyviruses (Alegbejo and Abo 2002; Ha et al. 2008; Matsumoto et al. 2016). PVMV was first identified in eastern Ghana in 1971 (Brunt and Kenten 1971). Since then, it has been reported in seven African countries including Senegal, Sierra Leone, Ivory Coast, Togo, Burkina Faso, Nigeria, and Tunisia (Arogundade et al. 2012; De Wijs 1973; Fajinmi and Odebode 2010; Gorsane et al. 2001; Hiskias et al. 1999; Huguenot et al. 1996; Tsai et al. 2010), and in several Asian countries including Yemen, India, China, and Japan (Cheng et al. 2009; Laina et al. 2019; Matsumoto et al. 2016; Walkey et al. 2010; Zhang et al. 2015). Naturally, PVMV infects fluted pumpkin (a species of the botanical family Cucurbitaceae) and a variety of Solanaceae species, such as pepper, tomato, tobacco, eggplant, petunia, Solanum nigrum L., S. integrifolim Poir., Datura metel, D. stramonium, Physalis angulata, and P. micrantha (Alegbejo 1999; Atiri 1986; Brunt et al. 1978; Givord 1982). Of these, pepper (C. annum) is the most wellcharacterized host susceptible to PVMV infection. Recently, six biologically cloned isolates of PVMV were obtained from $C$. annuum. These isolates induced rugosity, mosaic, and vein banding symptoms in C. annum plants (Laina et al. 2019). In addition, they consistently induced foliar mosaic and malformation symptoms in three model plants, Nicotiana benthamiana, $N$. clevelandii, and $N$. glutinosa (Laina et al. 2019). Although PVMV has been wellcharacterized from C. аnnuum, its pathology and impacts on the domesticated species, $C$. chinense, is not clear. In this study, a viral disease was reported in Yellow Lantern pepper, at an experimental station of Hainan University, China, which was found to be correlated with PVMV. Furthermore, an infectious cDNA clone of PVMV$\mathrm{HNu}$ isolate was generated, which was tested to validate a direct relationship between PVMV and foliar chlorosis and rugosity symptoms in $C$. chinense. This is the first study to represent the fulfillment of Koch's postulates for a disease in $C$. chinense using an infectious cDNA clone of PVMV.

In June 2017, a suspected viral infection was observed in Yellow Lantern at an experimental station of Hainan University, China, where about 100 Yellow Lantern plants were grown. Each plant was examined, and a total of 18 plants $(\sim 18 \%)$ showed symptoms 
suspected to be caused by viruses. In the early stage of the disease, Yellow Lantern plants showed foliar chlorosis along veins, which gradually developed into rugosity symptoms in the late stage (Supplementary Fig. S1). To test the transmissibility of the disease, eight healthy Yellow Lantern seedlings, maintained in a growth chamber, were rub-inoculated with the sap of one diseased sample $(\mathrm{HNu})$ from the field. Fifteen days postinoculation (dpi), all $\mathrm{HNu}-$ inoculated plants showed severe chlorosis along veins and rugosity symptoms, while they were absent in mock-inoculated plants (Supplementary Fig. S1). These results indicated that a transmissible agent, possibly a viral pathogen, was present in the diseased Yellow Lantern plants in the field.

To investigate if the disease was induced by a viral pathogen, leaf samples of the 18 diseased and 10 asymptomatic plants from the field were subjected to a diagnostic test of six viruses commonly found in pepper plants, PVMV, ChiRSV, ChiVMV, pepper yellow mosaic virus (PYMV), pepper severe mosaic virus (PSMV), and pepper mottle virus (PMV) using RT-PCR with the corresponding primer sets (Supplementary Table S1; Supplementary Materials and Methods). RT-PCR assays revealed that all diseased samples were positive for PVMV (Fig. 1A) and negative for the other five virus species, while no viruses were detected from the asymptomatic samples (data not shown). Furthermore, Yellow Lantern plants rub-inoculated with the sap of $\mathrm{HNu}$ (indicated in Supplementary Fig. S1) were positive for PVMV (Fig. 1B), indicating a close correlation between PVMV and foliar chlorosis and rugosity symptoms in Yellow Lantern. Given that $N$. benthamiana is an experimental host susceptible to PVMV infection (Cheng et al. 2009; Laina et al. 2019; Matsumoto et al. 2016), eight $N$. benthamiana plants were rub-inoculated with the sap of $\mathrm{HNu}$ to further validate the existence of PVMV in diseased Yellow Lantern plants in the field. Severe rugosity, deformation, and chlorosis systems were observed in systemic leaves of all $\mathrm{HNu}$-inoculated $N$. benthamiana plants, 30 dpi (Fig. 1C). In addition, extremely dwarfed phenotype was observed for these diseased plants (Fig. 1C). RT-PCR assay confirmed the presence of PVMV in diseased N. benthamiana plants (Fig. 1B).

Genomes of three PVMV isolates PVMV-ns1 (GenBank accession no. FJ617225), PVMV-HN from C. annuum in China (KR002568), and PVMV-P from C. frutescens in Ghana (DQ645484) have been sequenced. To determine the full-length sequence of the PVMV isolate $\mathrm{HNu}$, three primer sets (N'-L/N'-R, M'-L/M'-R, and C'-L/C'-R) (Supplementary Table S1) were designed to amplify three overlapping fragments along the PVMV-HNu genome (Supplementary Materials and Methods). The resulting PCR products, referred to as N', M', and C' (Supplementary Fig. S2), were cloned using NEBuilder HiFi DNA Assembly Master Mix (New England Biolabs). The $5^{\prime}$ - and $3^{\prime}$-terminal fragments were cloned using $5^{\prime}$ and $3^{\prime}$-rapid amplification of cDNA ends (RACE) kit (Invitrogen), respectively (Supplementary Fig. S2). More than three independent positive clones of each fragment were subjected to sanger sequencing (Sangon Biotech). The above five overlapping sequences were assembled to generate the complete genomic sequence of PVMV$\mathrm{HNu}$, which comprised 9,795 nucleotides (nt), excluding the $3^{\prime}$ terminal poly(A) sequence (Fig. 2A). This is deposited in GenBank database as accession number MN082715. The complete genome of PVMV-HNu contains a large open reading frame (ORF; 9,225 nt) encoding a polyprotein of 3,075 amino acids (aa). The ORF is flanked by a $5^{\prime}$ untranslated region (UTR) of 194-nt and a 3'-UTR of 376-nt (Fig. 2A). Basic Local Alignment Blast Analysis Tool (BLAST) analysis showed that the complete genome of PVMV-HNu shared 98.15, 98.17, and 97.9\% nt identities with PVMV-ns1, PVMV-P, and PVMV-HN, respectively. Sequence comparisons with the above three isolates revealed that a total of nine conserved cleavage sites, recognized by three viral proteases (P1, HC-Pro, or NIa-Pro), were predicted to cleave the polyprotein into 10 putative mature proteins (from the N-terminus): P1, HC-Pro, P3, 6K1, CI, 6K2, NIa-VPg, NIaPro, NIb, and CP (Fig. 2A). In addition, a putative small ORF (PIPO) embedded within the $\mathrm{P} 3$ cistron expressed through RNA polymerase slippage at GA6 (nt 2912 to 3142) (Chung et al. 2008; Olspert et al. 2015; Rodamilans et al. 2015), was also predicted (Fig. 2A).

To verify the correlation of PVMV with the disease in Yellow Lantern pepper, we constructed a full-length cDNA clone of PVMV-HNu, with a low-copy mini-binary T-DNA vector pCB301 (Xiang et al. 1999) as the backbone (Supplementary Fig. S3; Supplementary Materials and Methods). Briefly, a modified pCB301 vector with our desired multiple cloning sites (StuI-BamHI-PstI-AatII-SalI) was amplified from pVPH-GFP (Cui and Wang 2016). Three fragments (i.e., N, M, and C) along the entire genome of PVMV-HNu were amplified by RT-PCR. The Bam HI site at N-M junction was created artificially by mutating the nucleotide A (nt position 2363) into $\mathrm{C}$ during primer synthesis; however, this mutation did not alter the encoded amino acid. The fragments $(\mathrm{N}, \mathrm{C}$, and $\mathrm{M}$ ) were integrated step-by-step into the modified pCB301 vector with multiple cloning sites. Either pCB-N (containing fragment $\mathrm{N}$ ) or pCB-NC (containing fragment $\mathrm{N}-\mathrm{C}$ )

\section{A}
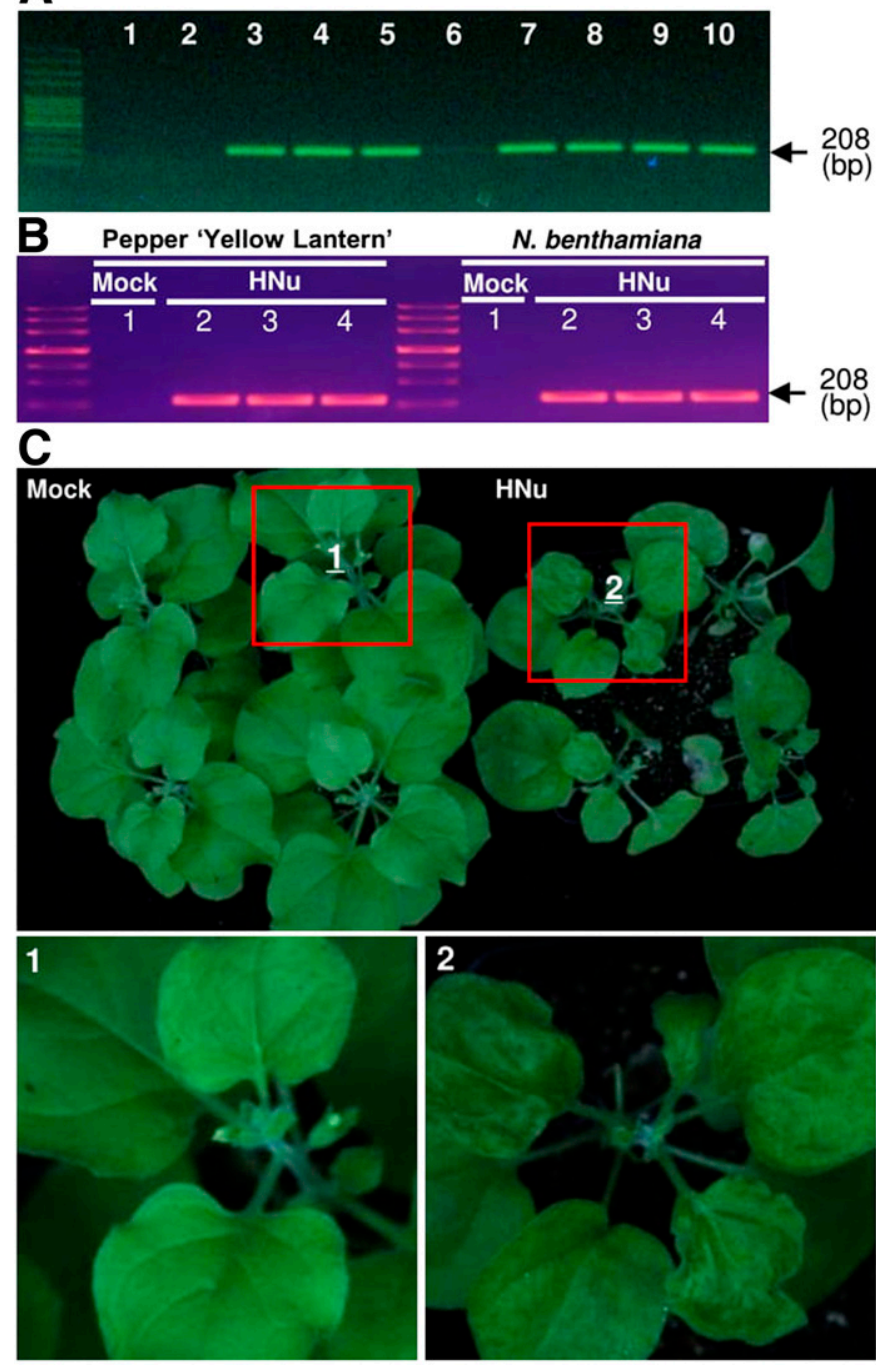

Fig. 1. Correlation of pepper veinal mottle virus (PVMV) with foliar chlorosis and rugosity symptoms in the pepper Yellow Lantern. A, RT-PCR detection of PVMV in Yellow Lantern plants in the field, with primer set PVMV-F/PVMVR (Supplementary Table S1). Lanes 1 and 2, asymptomatic samples; and lanes 3 to 10 , individual samples with foliar chlorosis and rugosity symptoms. $\mathbf{B}$, RT-PCR detection of PVMV from Yellow Lantern and Nicotiana benthamiana plants rub-inoculated with $\mathrm{HNu}$. Lanes 1 to 4 represent individual Yellow Lantern (indicated in Supplementary Fig. S1B) and N. benthamiana samples (indicated in C). C, Pathogenicity test of PVMV isolate $\mathrm{HNu}$ in $N$. benthamiana. The gray (red) rectangle shows a close-up view of the indicated regions. 


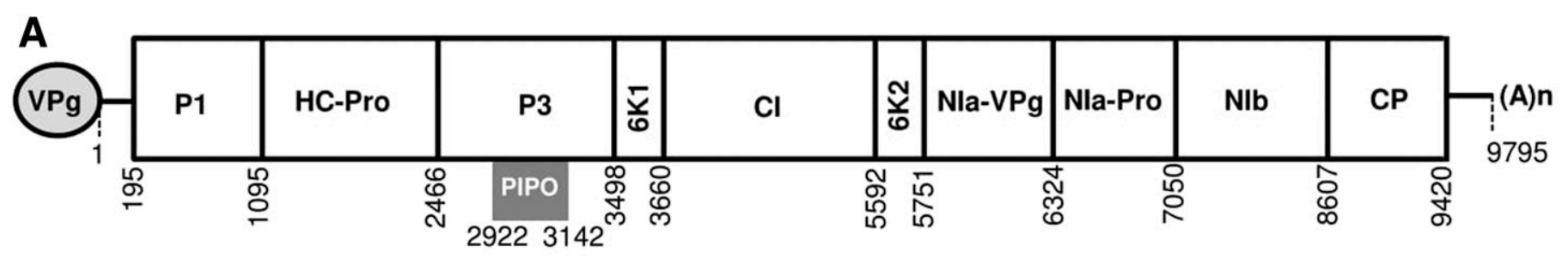

B
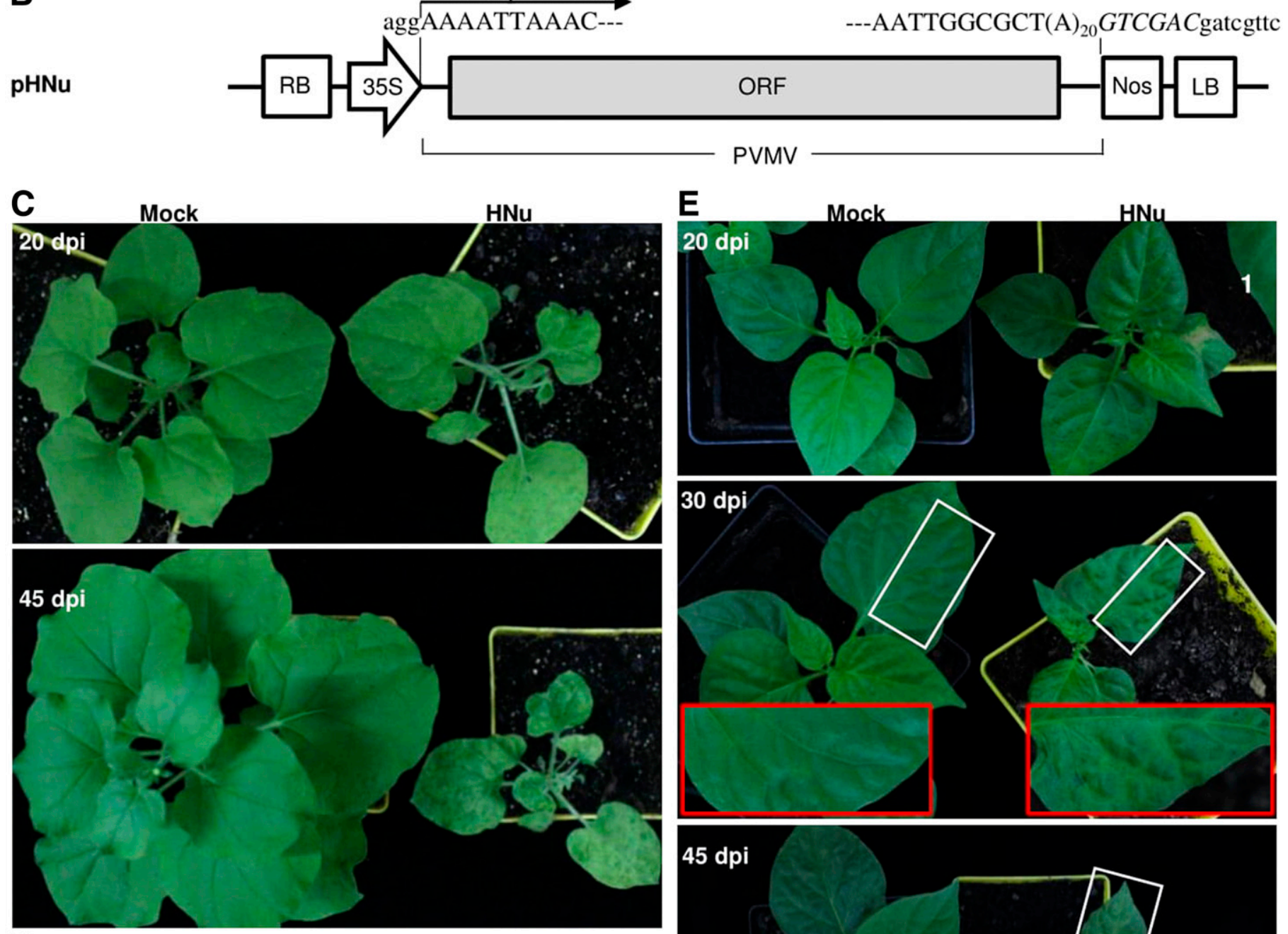

D

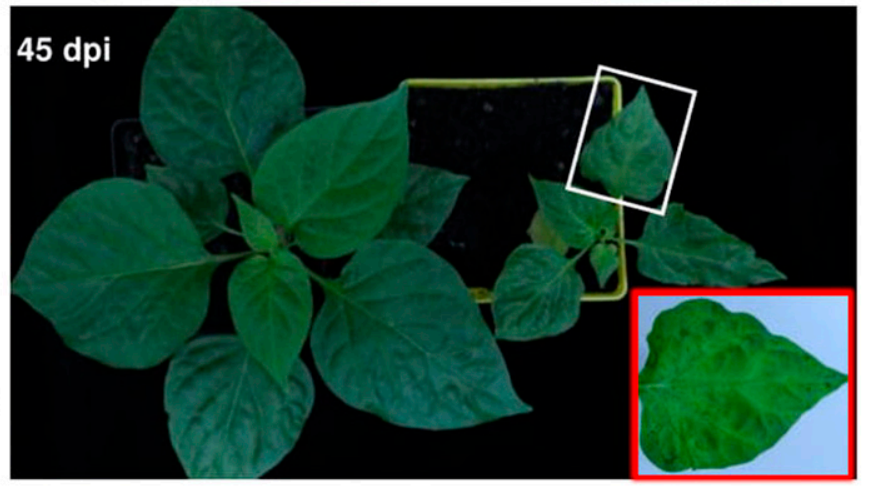

Fig. 2. Schematic representation of the genomic organization of pepper veinal mottle virus (PVMV)-HNu and development of its full-length infectious cDNA clone. A, Schematic representation of the genomic organization of PVMV-HNu. The two short horizontal lines show the $5^{\prime}$ - and $3^{\prime}$-untranslated regions. The large box represents the long open reading frame (ORF); the smaller boxes denote 10 putative mature proteins resulting from the proteolytic processing of the large polyprotein by viral self-encoded proteases. B, Diagram of PVMV-HNu-derived T-DNA construct ( $\mathrm{pHNu}$ ). The entire genomic cDNA of PVMV-HNu was introduced within the T-DNA borders of a low-copy mini-binary vector pCB301 (Xiang et al. 1999). The large box represents the long ORF encoding a large polyprotein of PVMV. The two short lines before and after the box represent the $5^{\prime}$ - and $3^{\prime}$-untranslated regions of PVMV, respectively. Above the diagram, the transcription start site is indicated by a bent arrow. Nucleotides belonging to pCB301 backbone are indicated in lowercase. Viral nucleotides are indicated in uppercase. PstI site is shown in italicized uppercase. C, Infectivity test of pHNu in Nicotiana benthamiana. Mock, infiltrated with agrobacterial cells containing empty vector pCB301. D, Transmission electron micrograph and RT-PCR detection of PVMV in $N$. benthamiana infiltrated with pHNu at 20 days postinoculation. Transmission electron microscopy assay was performed as previously described (Yang et al. 2019). Ten out of fifteen intact virions were measured, and a representative micrograph was shown. RT-PCR was carried out with primer set PVMV-F/PVMV-R (Supplementary Table S1). E, Infectivity test of pHNu in Yellow Lantern. The gray (red) rectangles show the close-up view of the indicated regions. 
was allowed to propagate in E. coli DH5 $\alpha$ cells. However, the ligation products for the generation of final PVMV clone $\mathrm{pHNu}$ (containing the entire cDNA of PVMV) failed to be transformed into $\mathrm{DH} 5 \alpha$ cells, implying that the $\mathrm{M}$ region containing the $\mathrm{P} 3$ coding sequence possibly conferred potential toxicity to certain E. coli strains, as suggested in other potyviruses (Gao et al. 2012; Johansen 1996; López-Moya and Garcia 2000; Yang et al. 1998). We attempted transformation of the ligation products in three other E. coli strains (TOP10, DH10B, and JM110), as well as an Agrobacterium tumefaciens strain (GV3101) via electroporation. Both TOP10 and DH10B strains are endonuclease (endA1)- and recombinase (recA1)-deficient, and possibly enhance the stability of foreign plasmids during propagation. Nonetheless, DH10B and GV3101 colonies containing the final vector $\mathrm{pHNu}$ were obtained, and no insertion, deletion, or mutation was found in the PVMV clones.

For the construction of infectious cDNA clone of a plant virus, a conventional strategy is to split the long viral genome into several fragments, followed by sequential integration into a binary plant expression vector. However, this strategy is not suitable for all viruses, since viral proteins could be toxic to $E$. coli, and the integrity of viral genome in the cDNA clone is compromised in certain E. coli strains (Pasin et al. 2018; Tuo et al. 2015, 2017). For potyviruses, the $\mathrm{P} 3$-coding region usually confers potential toxicity in $E$. coli, leading to insertion, mutation, and/or deletion of this region. Intron insertion in the $\mathrm{P} 3$-coding region is a widely used strategy to terminate the expression of undesired toxic proteins in E. coli (Desbiez et al. 2012; Gao et al. 2012; López-Moya and Garcia 2000; Yang et al. 1998). In this study, the low-copy mini-binary vector pCB301 was employed as the backbone to sequentially integrate the genomic portions of PVMV, with the fragment containing P3 coding region as the last integration. Both $E$. coli DH10B and A. tumefaciens GV3101 were screened for tolerating stable propagation of the final vector $\mathrm{pHNu}$ (containing the P3coding region). Recently, a similar strategy was adopted to develop the infectious cDNA clone of another potyvirus, plum pox virus (Cui and Wang 2016).

To test the infectivity of $\mathrm{pHNu}$, a total of $16 \mathrm{~N}$. benthamiana seedlings were infiltrated with an agrobacterial culture harboring the plasmid $\mathrm{pHNu}$, followed by daily examination of symptoms. At $20 \mathrm{dpi}$, the top leaves of all pHNu-infiltrated plants became extremely distorted and small (Fig. 2C). These diseased plants showed severe systemic chlorosis and dwarfism symptoms at 45 dpi; however, symptoms were absent in mock-inoculated controls (Fig. 2C). Flexuous filamentous particles, measuring approximately $850 \mathrm{~nm} \times 13 \mathrm{~nm}$, were observed in crude extracts of diseased plants (Fig. 2D). The RT-PCR assay further confirmed the presence of PVMV in diseased plants (Fig. 2D). To test whether pHNu is infectious in its natural host as well, 10 Yellow Lantern seedlings were agro-infiltrated with $\mathrm{pHNu}$, all of which showed obvious rugosity symptoms in newly developed leaves at $20 \mathrm{dpi}$ (Fig. 2E). At 30 and $45 \mathrm{dpi}$, severe symptoms such as foliar chlorosis along veins and rugosity were observed in systemic leaves (Fig. 2E). RT-PCR confirmed the presence of PVMV in these diseased Yellow Lantern plants. These results demonstrated that the complete cDNA clone of PVMV isolate $\mathrm{HNu}$ developed in this study is highly infectious in both experimental and natural hosts.

In summary, we identified PVMV from a suspected viral disease in $C$. chinense 'Yellow Lantern' and determined its close association with foliar chlorosis and rugosity symptoms. Pathogenicity test of the infectious cDNA clone of PVMV further supported the association. Given the high incidence of PVMV in Yellow Lantern, 18\% in this study and $74.07 \%$ in another recent report (Liang et al. 2015), an integrated management of PVMV in Hainan is urgently needed. More importantly, the complete cDNA clone of PVMV is infectious in both experimental and natural hosts (Fig. 2). Thus, this clone is the foundation for future studies on molecular virus-host interactions.

\section{ACKNOWLEDGMENTS}

We thank W. Qiu (W. H. Darr College of Agriculture, Missouri State University) for critical reading.

\section{LITERATURE CITED}

Alegbejo, M. D. 1999. Physalis micrantha L., a weed host of pepper veinal mottle virus. J. Veg. Crop Prod. 5:59-66.

Alegbejo, M. D., and Abo, M. E. 2002. Ecology, epidemiology and control of pepper veinal mottle virus (PVMV), genus Potyvirus, in West Africa. J. Sustain. Agric. 20:5-16.

Arogundade, O., Balogun, O. S., and Kareem, K. T. 2012. Occurrence and distribution of pepper veinal mottle virus and cucumber mosaic virus in pepper in Ibadan, Nigeria. Virol. J. 9:79.

Atiri, G. I. 1986. A disease of fluted pumpkin (telfairia occidentalis Hook.f.) caused by a yellow vein clearing strain of pepper veinal mottle virus in Nigeria. J. Plant Prot. Trop. 2:105-110.

Brunt, A. A., and Kenten, R. H. 1971. Pepper veinal mottle virus-A new member of the potato virus $\mathrm{Y}$ group from peppers (Capsicum annuиm L. and C. frutescens L.) in Ghana. Ann. Appl. Biol. 69:235-243.

Brunt, A. A., Kenten, R. H., and Phillips, S. 1978. Symptomatologically distinct strains of pepper veinal mottle virus from four West African solanaceous crops. Ann. Appl. Biol. 88:115-119.

Cheng, Y. H., Wang, R., Chen, C. C., Chang, C. A., and Jan, F. 2009. First report of pepper veinal mottle virus in tomato and pepper in Taiwan. Plant Dis. 93:107.

Chung, B. Y., Miller, W. A., Atkins, J. F., and Firth, A. E. 2008. An overlapping essential gene in the Potyviridae. Proc. Natl. Acad. Sci. USA 105: 5897-5902.

Cui, H., and Wang, A. 2016. Plum pox virus 6K1 protein is required for viral replication and targets the viral replication complex at the early stage of infection. J. Virol. 90:5119-5131.

De Wijs, J. J. 1973. Pepper veinal mottle virus in Ivory Coast. Eur. J. Plant Pathol. 79:189-193.

Desbiez, C., Chandeysson, C., Lecoq, H., and Moury, B. 2012. A simple, rapid and efficient way to obtain infectious clones of potyviruses. J. Virol. Methods 183:94-97.

Fajinmi, A. A., and Odebode, C. A. 2010. Evaluation of maize/pepper intercropping model in the management of pepper veinal mottle virus, genus Potyvirus, family Potyviridae on cultivated pepper (Capsicum annuиm L.) in Nigeria. Arch. Phytopathol. Plant Prot. 43:1524-1533.

Gao, R., Tian, Y. P., Wang, J., Yin, X., Li, X. D., and Valkonen, J. P. T. 2012. Construction of an infectious cDNA clone and gene expression vector of tobacco vein banding mosaic virus (genus Potyvirus). Virus Res. 169: 276-281.

Givord, L. 1982. Pepper veinal mottle virus in the weed Physalis angulata in the Ivory Coast. Plant Dis. 66:1081-1082.

Gorsane, F., Fakhfakh, H., Tourneur, C., Marrakchi, M., and Makni, M. 2001. Nucleotide sequence comparison of the $3^{\prime}$ terminal region of the genome of pepper vein mottle virus isolates from Tunisia and Ivory Coast. Arch. Virol. 146:611-618.

Ha, J. H., Hong, J. S., Kim, T., and Ryu, K. 2008. Complete genome sequence of an isolate of pepper veinal mottle virus and phylogenetic relationship with other potyviruses. Arch. Virol. 153:2315-2318.

Hiskias, Y., Lesemann, D. E., and Vetten, H. J. 1999. Occurrence, distribution and relative importance of viruses infecting hot pepper and tomato in the major growing areas of Ethiopia. J. Phytopathol. 147:5-11.

Huguenot, C., Furneaux, M. T., Clare, J., and Hamilton, R. I. 1996. Serodiagnosis of pepper veinal mottle virus in West Africa using specific monoclonal antibodies in DAS-ELISA. J. Phytopathol. 144:29-32.

Johansen, I. E. 1996. Intron insertion facilitates amplification of cloned virus cDNA in Escherichia coli while biological activity is reestablished after transcription in vivo. Proc. Natl. Acad. Sci. USA 93:1240012405.

Laina, J. A., Matsumoto, K., Setoyama, T., Kawano, S., and Ohshima, K. 2019. Pepper veinal mottle virus in Japan is closely related to isolates from other Asian countries, but more distantly to most of those from Africa. Virus Genes 55:347-355.

Liang, J., Wang, J., Zhang, S., Yu, N., Zhang, Y., Wang, X., and Liu, Z. 2015. Identification and detection of pepper veinal mottle virus in Hainan. Chin. J. Trop. Crops 36:966-971.

López-Moya, J. J., and Garcia, J. A. 2000. Construction of a stable and highly infectious intron-containing cDNA clone of plum pox potyvirus and its use to infect plants by particle bombardment. Virus Res. 68:99-107.

Matsumoto, K., Yasaka, R., Setoyama, T., Kawano, S., and Ohshima, K. 2016. Chilli pepper rugose mosaic disease caused by pepper veinal mottle virus occurs on Ishigaki Island, Japan. J. Gen. Plant Pathol. 82:57-60. 
Olspert, A., Chung, B. Y., Atkins, J. F., Carr, J. P., and Firth, A. E. 2015. Transcriptional slippage in the positive-sense RNA virus family Potyviridae. EMBO Rep. 16:995-1004.

Pasin, F., Tseng, X., Bedoya, L. C., Heydarnejad, J., Deng, T., Garcia, J. A., and Chen, Y. 2018. Streamlined generation of plant virus infectious clones using the pLX mini binary vectors. J. Virol. Methods 262:48-55.

Rodamilans, B., Valli, A., Mingot, A., Leon, D. S., Baulcombe, D. C., Lopezmoya, J. J., and Garcia, J. A. 2015. RNA polymerase slippage as a mechanism for the production of frameshift gene products in plant viruses of the Potyviridae family. J. Virol. 89:6965-6967.

Tsai, W. S., Abdourhamane, I. K., and Kenyon, L. 2010. First report of pepper veinal mottle virus associated with mosaic and mottle diseases of tomato and pepper in Mali. Plant Dis. 94:378.

Tuo, D., Fu, L., Shen, W., Li, X., Zhou, P., and Yan, P. 2017. Generation of stable infectious clones of plant viruses by using Rhizobium radiobacter for both cloning and inoculation. Virology 510:99-103.

Tuo, D., Shen, W., Yan, P., Li, X., and Zhou, P. 2015. Rapid Construction of stable infectious full-length cDNA clone of papaya leaf distortion mosaic virus using in-fusion cloning. Viruses 7:6241-6250.

Walkey, D. G. A., Spence, N. J., Clay, C. M., and Miller, A. 2010. A potyvirus isolated from solanaceous hosts. Plant Pathol. 43:931-937.
Wang, J. 2012. Characterization of viruses on Capsicum chinense in Hainan and interference with ChiRSV infection utilizing double-strand RNA. Thesis, Hainan University.

Wang, J., Liu, Z., Niu, S., Peng, M., Wang, D., Weng, Z., and Xiong, Z. 2006. Natural occurrence of chilli veinal mottle virus on Capsicum chinense in China. Plant Dis. 90:377.

Xiang, C., Han, P., Lutziger, I., Wang, K., and Oliver, D. J. 1999. A mini binary vector series for plant transformation. Plant Mol. Biol. 40:711-717.

Yang, K., Shen, W., Li, Y., Li, Z., Miao, W., Wang, A., and Cui, H. 2019. Areca palm necrotic ringspot virus, classified within a recently proposed genus Arepavirus of the family Potyviridae, is associated with necrotic ringspot disease in areca palm. Phytopathology 109:887-894.

Yang, S. J., Revers, F., Souche, S., Lot, H., Gall, O. L., Candresse, T., and Dunez, J. 1998. Construction of full-length cDNA clones of lettuce mosaic virus (LMV) and the effects of intron-insertion on their viability in Escherichia coli and on their infectivity to plants. Arch. Virol. 143: 2443-2451.

Zhang, S., Zhao, Z., Zheng, L., Liu, J., Peng, J., Yan, F., Li, F., Xie, Y., Cheng, Z., Zhou, X., Zhang, D., and Liu, Y. 2015. Complete genome analysis of a novel recombinant isolate of pepper veinal mottle virus from mainland China. Virol. J. 12:191. 